\title{
DNA methylation profiling identifies the HOXA11 gene as an early diagnostic and prognostic molecular marker in human lung adenocarcinoma
}

\author{
Qun Li ${ }^{1,2, *}$, Chang Chen ${ }^{3}$, Xiaohui Ren ${ }^{1}$, Weihong Sun ${ }^{1, *}$ \\ ${ }^{1}$ Key Laboratory of Stem Cell Biology, Institute of Health Sciences, Shanghai Institutes for Biological Sciences, Chinese \\ Academy of Sciences, Shanghai Jiao Tong University School of Medicine, Shanghai, 200031, China \\ ${ }^{2}$ The State Key Laboratory of Medical Genomics, Shanghai Key Laboratory of Hypertension, Ruijin Hospital, Shanghai \\ Institute of Hypertension, Shanghai Jiao Tong University School of Medicine, Shanghai, 200025, China \\ ${ }^{3}$ Department of Orthodontics, The First Affiliated Hospital of Zhengzhou University, Stomatological College Zhengzhou \\ University, Zhengzhou, 450052, China \\ "These authors contributed equally to this work
}

Correspondence to: Weihong Sun, email: whsun01@sibs.ac.cn

Keywords: HOXA11, hypermethylation, lung adenocarcinoma, adenocarcinoma in situ, prognosis

Received: October 11, $2016 \quad$ Accepted: March 14, $2017 \quad$ Published: March 23, 2017

Copyright: Li et al. This is an open-access article distributed under the terms of the Creative Commons Attribution License (CC-BY), which permits unrestricted use, distribution, and reproduction in any medium, provided the original author and source are credited.

\section{ABSTRACT}

DNA hypermethylation plays important roles in carcinogenesis by silencing key genes. The goal of our study was to identify pivotal genes using MethyLight and assessed their diagnostic and prognostic values in lung adenocarcinoma (AD). In the present study, we detected DNA methylation at sixteen loci promoter regions in twenty one pairs of primary human lung AD tissues and adjacent non-tumor lung (AdjNL) tissues using the real-time PCR (RT-PCR)-based method MethyLight. By comparing the sixteen analyzed loci in lung AD tissues and AdjNL and non-tumor (NL) tissues, we found that, among the six genes identified with hypermethylation, the HOXA11, CDKN2A-EX2 and EYA4 genes showed highly promising DNA hypermethylation diagnostic markers in the lung AD tissues. Moreover, comparing lung AD tissues ( $>2 \mathrm{~cm}$ in diameter) to the AdjNL or AD in situ (AIS) tissues by RT-qPCR and immunohistochemistry revealed that HOXA11 expression was significantly increased. A further study showed that HOXA11 expression was controlled by methylation in the promoter region in human lung tumor cell lines. Aberrant hypermethylation and the methylation-induced down-regulation of HOXA11 may promote tumor progression. Our results suggested that HOXA11 might be a diagnostic and prognostic marker in patients with lung $A D$.

\section{INTRODUCTION}

The morbidity and mortality of lung cancer is increasing most rapidly these years in China. In histology, lung cancers are classified into two main types, including non-small cell lung carcinoma (NSCLC) and small cell lung carcinoma (SCLC). The three major subtypes of NSCLC are AD, squamous-cell carcinoma and largecell carcinoma. Among them, AD is the remarkable histological subtype and its incidence is raising [1]. The 5 -year survival rate of AD is about $15 \%$ [2], normally, its mortality rate is high, because the early diagnosis is difficult and its progress is very quickly. Although some clinicopathological features, including tumor size, vascular invasion and histopathological grade, have been shown to be prognostic factors for lung cancer after surgical resection, its prognostic molecular markers have not been well documented. Therefore, the identification of diagnostic and prognostic molecular markers is scientifically and clinically significant. These markers may help reveal the mechanisms of lung $\mathrm{AD}$, serve as potential therapeutic targets and predict patient prognosis.

On the basis of its clinicopathological features, $\mathrm{AD}$ has been considered to develop into invasive carcinoma through atypical adenomatous hyperplasia (AAH), AIS, and minimally invasive AD [3]. In 1999, the 
histological classification of lung cancer was renewed by the World Health Organization, both bronchioloalveolar carcinoma (BAC) and AAH were added as a very early stage of $\mathrm{AD}$ (AIS) [4]. Therefore, they were considered as early manifestation of AD. Furthermore, Small AD (two centimeters or less in diameter) can be divided into two groups, including replacement type $\mathrm{AD}$ and Non-replacement type AD. Each group can be further subdivided into three types, respectively. The subtypes of replacement type AD contain Localized bronchioloalveolar carcinoma (LBAC, type A), LBAC with foci of collapse of alveolar structure (type B) and LBAC with foci of active fibroblastic proliferation (type C), the subtypes of Non-replacement type AD incorporate poorly differentiated $\mathrm{AD}$ (type $\mathrm{D}$ ), tubular $\mathrm{AD}$ (type $\mathrm{E}$ ) and papillary $\mathrm{AD}$ with compressive and destructive growth (type F) [5]. The above type A, B and C are considered to be early stage of AD. Patients with type $\mathrm{A}$ and $\mathrm{B}$ have a very good prognosis, and the 5-year survival rate is $100 \%$ [6]. The change of DNA methylation pattern is the best features and the easiest quantifiable epigenetic alteration in lung $\mathrm{AD}$ [7]. It is possible that DNA methylation detection is used for cancer screening. In most of the previous studies, a candidate gene approach was used for DNA methylation testing in lung cancer. DNA hypermethylation at promoter region indicates much probably as a cancer-specific marker, it can complement visual tools for lung cancer screening, such as chest radiography and spiral CT, thereby improving early diagnosis. DNA methylation plays an important role in carcinogenesis because it leads to the silencing of many pivotal genes, including tumor suppressor genes [8]. DNA hypermethylation in promoter region occures in all cancers, which can induce the downstream gene silence through the methylation of $\mathrm{CpG}$ islands close to the transcriptional initiation sites of genes. Among many DNA molecular markers, DNA hypermethylation is a great promise epigenetic alteration marker.

In this study, we focused on lung $\mathrm{AD}$ and identified pivotal hypermethylated genes by using the MethyLight method [9]. We chose 16 loci that showed hypermethylation in promoter region of lung and other kinds of cancers reported by other researchers, and these genes played important roles in transcription, tumor suppressor, apoptosis and cell cycle modulation (Table 1). We found that 6 genes showed hypermethylation in human lung $\mathrm{AD}$ tissues. Then, among the 6 hypermethylated genes, we screened for potential prognosis-related genes using AIS tissues and AD tissues. We discovered that HOXA11 was hypermethylated at the early stage of human lung $\mathrm{AD}$ and further investigated its diagnostic and prognostic value.

\section{RESULTS}

\section{DNA methylation profile in lung AD tissues by MethyLight analysis}

To identify aberrantly methylated genes in lung $\mathrm{AD}$, we selected the MethyLight method to check the methylation status of promoter regions in lung $\mathrm{AD}$ tissues compared to that in AdjNL and control NL tissues. Sixteen loci (Table 1) were chosen in this study. These loci are in the promoter region and have rich $\mathrm{CpG}$ islands, which are the part of key factors in tumor suppressor, cell cycle regulation, apoptosis and transcription (Table 1).

We analyzed the DNA methylation from 16 loci in 21 paired human lung AD and AdjNL tissues and $2 \mathrm{NL}$ tissues, the results were illustrated in Figure 1A. DNA methylation was presented by using PMR and then visualized by using color coding as follows: DNA methylation level above the median (PMR $>25$, red), below the median $(5<$ PMR $<25$, yellow $)$ and no detectable DNA methylation (PMR $<5$, green). A comparison of the AD and AdjNL tissues was shown in Figure 1A, demonstrating that the six loci (HOXA11, CDKN2A EX2, EYA4, HOXA1, CDX2 and TWEFF2) showed highly significant hypermethylation in lung AD $(p<0.01)$, particularly in the following loci: HOXA11 $(p=6.86 \mathrm{E}-05), \mathrm{CDKN} 2 \mathrm{~A} \mathrm{EX} 2(p=1.85 \mathrm{E}-04)$, and EYA4 $(p=8.41 \mathrm{E}-04)$. We also analyzed the top three markers in all samples and samples based on gender, stage and Noguchi classification (Table 2). The results showed that HOXA11, CDKN2A EX2 and EYA4 were hypermethylated even in AIS samples.

We checked the relevance between the top six hypermethylated genes and the three different tissues (lung $\mathrm{AD}$, AdjNL and NL tissues) by using twodimensional hierarchical clustering analysis (Figure 1B). Six loci, HOXA1, HOXA11, CDX2, EYA4, TWEFF2 and CDKN2A EX2, clustered together (left), showing significant methylation in the lung AD (top left) samples.

We further analyzed the receiver operating characteristic (ROC) curve using the SPSS statistics software. As shown in Figure 2, the area under the curve (AUC, which indicates a marker performance), that is equal to 1 for a marker meaning $100 \%$ specificity and sensitivity, AUC is $0.83-0.91$ for the three top loci as follows: HOXA11 $(\mathrm{AUC}=0.91), \mathrm{CDKN} 2 \mathrm{~A} \mathrm{EX} 2(\mathrm{AUC}=0.90)$, and EYA4 $(A U C=0.83)$. These three genes, particularly the HOXA11 and CDKN2A EX2 genes, can much probably be taken as new DNA hypermethylation markers for early diagnosis in lung AD. Thus, these data suggested that HOXA11 and CDKN2A EX2 might be DNA hypermethylation markers for lung $\mathrm{AD}$. 
Table 1: Gene name and function of the 16 loci studied

\begin{tabular}{|c|c|c|}
\hline Official symbol & Official Full Name ${ }^{a}$ & Function ${ }^{a}$ \\
\hline CDH13 & cadherin 13 & Cell-cell adhesions. \\
\hline CDKN2A & cyclin-dependent kinase inhibitor $2 \mathrm{~A}$ & $\begin{array}{l}\text { Tumor suppressor. Cell cycle control. involved in } \\
\text { proliferation and apoptosis }\end{array}$ \\
\hline CDX2 & caudal type homeobox 2 & $\begin{array}{l}\text { Transcriptional regulation. Involved in cell growth } \\
\text { and differentiation. }\end{array}$ \\
\hline CYP2C 35 & cytochrome P450 2C35 & Unknown. \\
\hline EYA4 & EYA transcriptional coactivator and phosphatase 4 & Transcription regulation. Involved in development \\
\hline HOXA1 & homeobox A1 & Transcription factor. Involved in development \\
\hline HOXA11 & homeobox A11 & Transcription factor. \\
\hline NEUROD1 & neurogenic differentiation 1 & Transcriptional activator. Involved in differentiation. \\
\hline NEUROD2 & neurogenic differentiation 2 & Transcriptional activity. Involved in development \\
\hline ONECUT2 & one cut homeobox 2 & Transcriptional factor. \\
\hline OPCML & $\begin{array}{l}\text { opioid binding protein/cell adhesion molecule- } \\
\text { like }\end{array}$ & Involve in cell contact \\
\hline PTPRN2 & $\begin{array}{l}\text { protein tyrosine phosphatase, receptor type, } \mathrm{N} \\
\text { polypeptide } 2\end{array}$ & $\begin{array}{l}\text { Regulate a variety of cellular processes including cell } \\
\text { growth, differentiation, mitotic cycle, and oncogenic } \\
\text { transformation }\end{array}$ \\
\hline RASSF1 & $\begin{array}{l}\text { Ras association (RalGDS/AF-6) domain family } \\
\text { member } 1\end{array}$ & $\begin{array}{l}\text { Potential tumor suppressor. Involved in apoptosis, } \\
\text { proliferation, cell cycle progression. }\end{array}$ \\
\hline SFRP1 & Secreted frizzled-related protein 1 & $\begin{array}{l}\text { Epigenetic silencing of SFRP genes leads to } \\
\text { deregulated activation of the Wnt-pathway }\end{array}$ \\
\hline TMEFF2 & $\begin{array}{l}\text { transmembrane protein with EGF-like and two } \\
\text { follistatin-like domains } 2\end{array}$ & Down-regulated in tumor cell lines. \\
\hline TWIST1 & Twist family bHLH transcription factor 1 & Transcription factor. Involved in differentiation. \\
\hline
\end{tabular}

${ }^{a}$ Approved gene name and function from National Center for Biotechnology Information(NCBI) .

website http://www.ncbi.nlm.nih.gov/

\section{Expression of HOXA11, EYA4 and CDKN2A in human AD and AdjNL tissues}

We investigated the top three hypermethylation genes (HOXA11, EYA4 and CDKN2A) mRNA expression using RT-qPCR in lung AD tissues and AdjNL tissues. The relative mRNA expression of HOXA11 and EYA4 was significantly higher in AdjNL than that in lung AD tissues (Figure 3A and 3B), whereas CDKN2A expression was not significantly different (Figure 3C). Our results revealed that the promoter hypermethylation of HOXA11 and EYA4 could down-regulate their mRNA expression.

\section{Effect of HOXA11 expression on 5-AZA-dC induced-lung AD cell lines}

We chose eight human lung cancer cell lines from our cell bank to detect HOXA11 protein expression by a western blot estimation of the HOXA11 protein band intensity normalized to Tubulin (Figure 4A). Then, we selected the two lung AD cell lines 95D and A549 and stimulated these cell lines with or without 5-AZA-dC; we found that the HOXA11 mRNA expression and protein release were significantly restored in both cell lines after the 5-AZA-dC stimulation (Figure 4B, 4C). Our results revealed that 5-AZA-DC could restore HOXA11 protein expression.

\section{Comparison of HOXA11 gene expression in lung AD, AIS and AdjNL tissues by immunohistochemical staining}

To estimate the clinical significance of HOXA11, we investigated the HOXA11 protein expression in TMA from 160 lung cancer patients by using immunohistochemical analysis. For the histological analysis, sections taken from human lung AD $(>2 \mathrm{~cm})$, AIS and AdjNL tissues were stained for the HOXA11 protein. We found that 
HOXA11 protein expression was lower in lung AD tissues than in the AIS and AdjNL tissues. However, there were no significant differences between the AIS and AdjNL tissues (Figure 5A, 5C). HOXA11 protein expression was mainly observed in the nucleus (Figure 5A). In addition, HOXA11 protein expression had an inverse relationship with the tumor clinicopathological type, with lower HOXA11 protein levels in AD tissues compared to those in AIS tissues. The HOXA11 IHC scores illustrated that the AD tissues had a lower HOXA11 protein level than the AIS and AdjNL tissues ( $p<0.0001)$ (Figure 5B).

\section{DISCUSSION}

Many cancers studies have reported that the principal mechanisms of the inactivation of tumor suppressor genes is the hypermethylation of promoter regions associated with gene silencing $[10,11]$. In the last two decades, the roles of epigenetic modifications, particularly DNA methylation, in carcinogenesis and its progression have attracted increasing attention $[12,13]$. In our present study, we sought to identify the pivotal genes and assess their prognostic values and molecular mechanism in lung AD. MethyLight method was used to check the methylation status in the promotor regions of sixteen loci in lung AD tissues and AdjNL tissues. The 16 loci (Table 1) chosen for the DNA methylation analysis have been demonstrated to be hypermethylated in lung or the other kinds of cancers, and all these genes play key roles in cell cycle modulation, DNA repair, transcription, and apoptosis, thus, for our study, we selected these loci for further analysis. Taken from our above results, three loci can much probably be taken as DNA hypermethylation markers for the early stage of lung AD. These loci are HOXA11, CDKN2A EX2 and EYA4. The ROC curve shows that the AUC is 0.83-0.91 for the top three genes as follows: HOXA11 $(\mathrm{AUC}=0.91), \mathrm{CDKN} 2 \mathrm{~A} \mathrm{EX} 2(\mathrm{AUC}=0.90)$, and EYA4 $(A U C=0.83)$. The HOXA11 and CDKN2A genes appear to be highly promising DNA hypermethylation markers for the development of non-invasive molecular markers of lung AD. These results are consistent with previous findings $[14,15]$. Then, we chose these three genes for the further study of their mRNA and protein expression. Interestingly, we found that the HOXA11 protein was significantly higher in AIS than that in AD. This result has not yet been reported in the literature. Our results indicated that HOXA11 could serve as a potential therapeutic target and predicts patients' prognosis after a surgical operation.
A

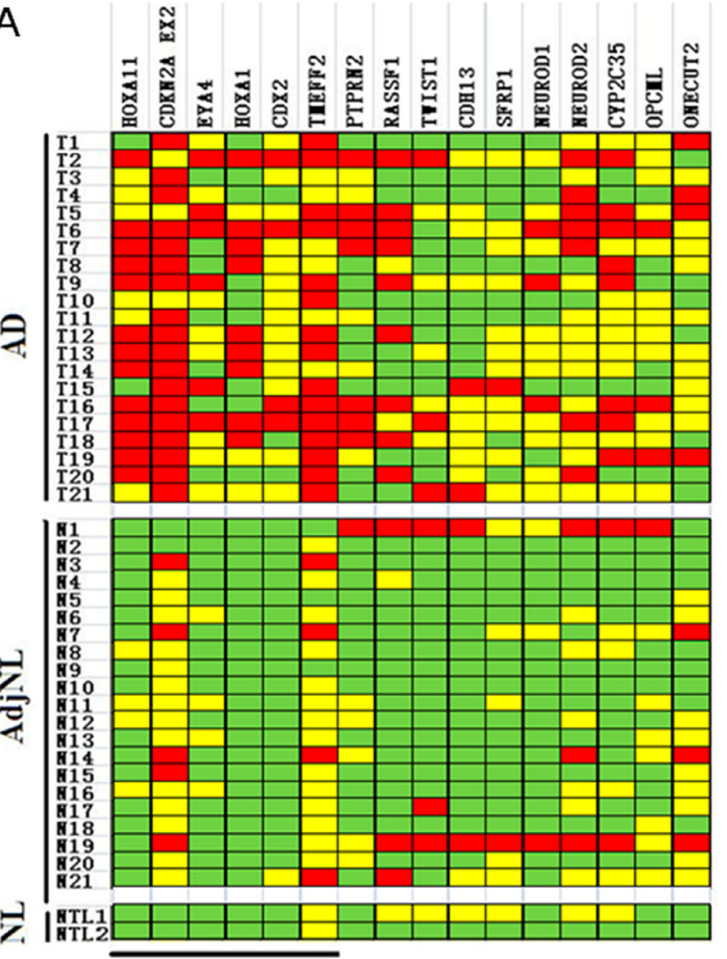

B

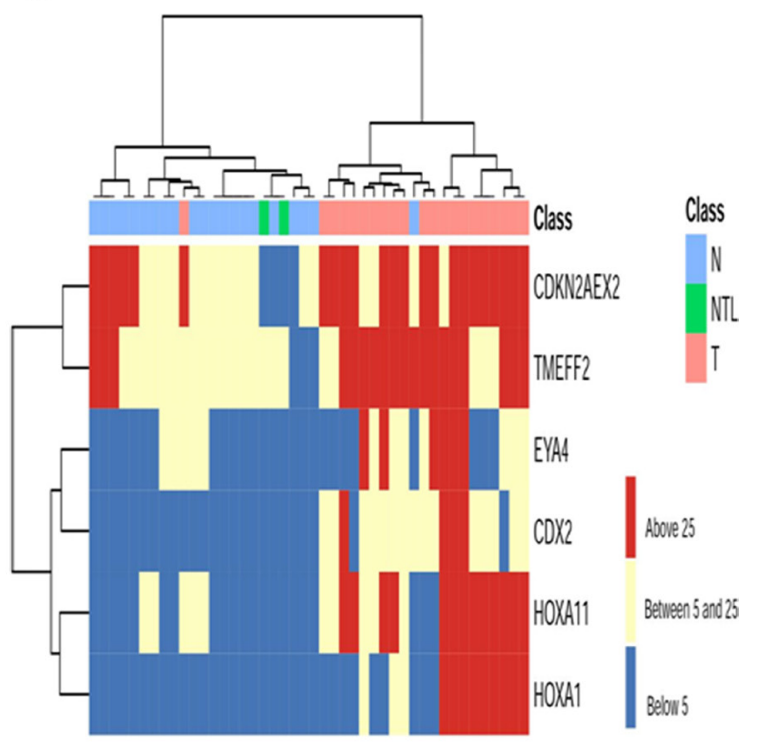

Figure 1: DNA methylation profile in lung AD tissues by MethyLight analysis. (A) Graphic representation of PMR values obtained from 16 loci in AD, AdjNL and NL samples. Samples are indicated on the left (the same number indicates that the sample is from the same patient) and loci are indicated on the top. PMR values have been categorized as colored boxes denoting DNA methylation above the median $(\mathrm{PMR}>25$, red), below the median $(5<\mathrm{PMR}<25$, yellow) and no detectable DNA methylation (PMR $<5$, green). The black bar at the bottom indicates loci showing statistically significant differences in DNA methylation levels between AD and AdjNL. (B) Twodimensional hierarchical clustering of samples and the top 6 loci based on DNA methylation data. DNA methylation levels are indicated by the color shown on the right side. The ward hierarchical clustering method was used to categorize the AD, AdjNL and NL samples. Samples are indicated on the top line, with AD in pink, AdjNL samples in green, and NL samples in blue. 
Table 2: Performance of top three markers in total samples and samples based on gender, stage and noguchi classification

\begin{tabular}{|c|c|c|c|}
\hline & Median PMR,Tumor & Median PMR.AdjNL & $p$-value ${ }^{a}$ \\
\hline Total samples & $n=21$ & $n=21$ & \\
\hline HOXA11 & 48.80 & 3.03 & $6.9 \mathrm{E}-05$ \\
\hline CDKN2A & 48.90 & 18.10 & 1.8E-04 \\
\hline EYA4 & 18.98 & 2.52 & 8.4E-04 \\
\hline \multicolumn{4}{|l|}{ GENDER } \\
\hline Femal & $n=12$ & $n=12$ & \\
\hline HOXA11 & 38.13 & 1.36 & 3.5E-03 \\
\hline CDKN2A & 42.97 & 20.32 & 5.9E-03 \\
\hline EYA4 & 13.41 & 1.85 & 1.4E-02 \\
\hline Meal & $n=9$ & $n=9$ & \\
\hline HOXA11 & 63.02 & 5.09 & 2.3E-03 \\
\hline CDKN2A & 56.81 & 11.78 & 2.4E-03 \\
\hline EYA4 & 26.40 & 3.01 & 1.2E-02 \\
\hline \multicolumn{4}{|l|}{ STAGE $^{\mathrm{b}}$} \\
\hline StageIA & $n=15$ & $n=15$ & \\
\hline HOXA11 & 44.59 & 2.69 & 2.2E-03 \\
\hline CDKN2A EX2 & 52.19 & 21.45 & 4.7E-03 \\
\hline EYA4 & 15.73 & 2.59 & 9.6E-03 \\
\hline StageIB & $\mathrm{n}=2$ & $n=2$ & \\
\hline HOXA11 & 76.67 & 2.93 & 4.2E-01 \\
\hline CDKN2A EX2 & 33.21 & 7.07 & $2.8 \mathrm{E}-01$ \\
\hline EYA4 & 42.55 & 0.99 & $9.8 \mathrm{E}-02$ \\
\hline StageIIA/IIB/IIIA & $n=4$ & $n=4$ & \\
\hline HOXA11 & 50.66 & 4.34 & 6.8E-03 \\
\hline CDKN2A EX2 & 44.41 & 11.04 & 3.7E-02 \\
\hline EYA4 & 19.38 & 3.00 & 2.8E-01 \\
\hline \multicolumn{4}{|c|}{ Noguchi classification } \\
\hline TypeA,B & $n=15$ & $n=15$ & \\
\hline HOXA11 & 48.43 & 2.95 & 8.8E-04 \\
\hline CDKN2A EX2 & 51.65 & 20.38 & $4.5 \mathrm{E}-03$ \\
\hline EYA4 & 13.96 & 2.64 & 2.1E-02 \\
\hline$>2 \mathrm{~cm}$ & $n=6$ & $n=6$ & \\
\hline HOXA11 & 49.73 & 3.22 & $5.7 \mathrm{E}-02$ \\
\hline CDKN2A EX2 & 42.02 & 12.40 & 3.6E-03 \\
\hline EYA4 & 31.54 & 2.23 & $1.6 \mathrm{E}-02$ \\
\hline
\end{tabular}

Homeobox sequences contain a helix-turn-helix DNA binding motif and encode 60 -amino-acid homeodomain [16]. The HOXA11 gene is part of the cluster named A on chromosome 7 , which is a region frequently deleted in human cancers. A DNA-binding transcription factor modulating gene expression, differentiation and morphogenesis was encoded in HOXA11 protein, and this gene played important roles in the development of uterine and female fertility [17].
HOXA11 is hypermethylated in lung AD even in the early stage IA tissues [18]. Similarly, here, we demonstrate that HOXA11 is hypermethylated in lung AD. Moreover, in the present study, the AIS samples were from the patients who had 100\% 5-year survival rate, in another study had gotten the survival rate of AD is about $15 \%$ [2]. So our result showed that the down-regulated expression of the HOXA11 gene was associated with worse survival rates. 

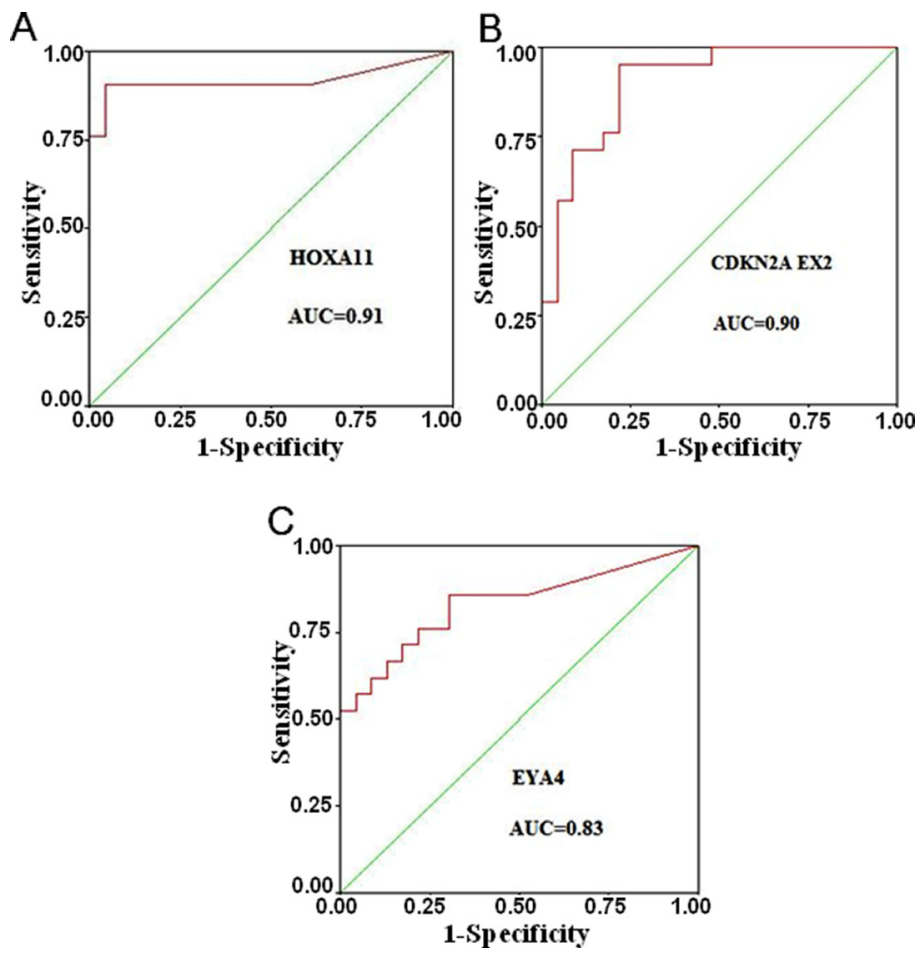

Figure 2: Receiver operating characteristic (ROC) curves for the three top markers. The AUC (This indicates of marker performance that would be 1 for a marker showing 100\% specificity and sensitivity) is $0.83-0.91$ for the three top loci (A) HOXA11, (B) CDKN2A EX2 and (C) EYA4.
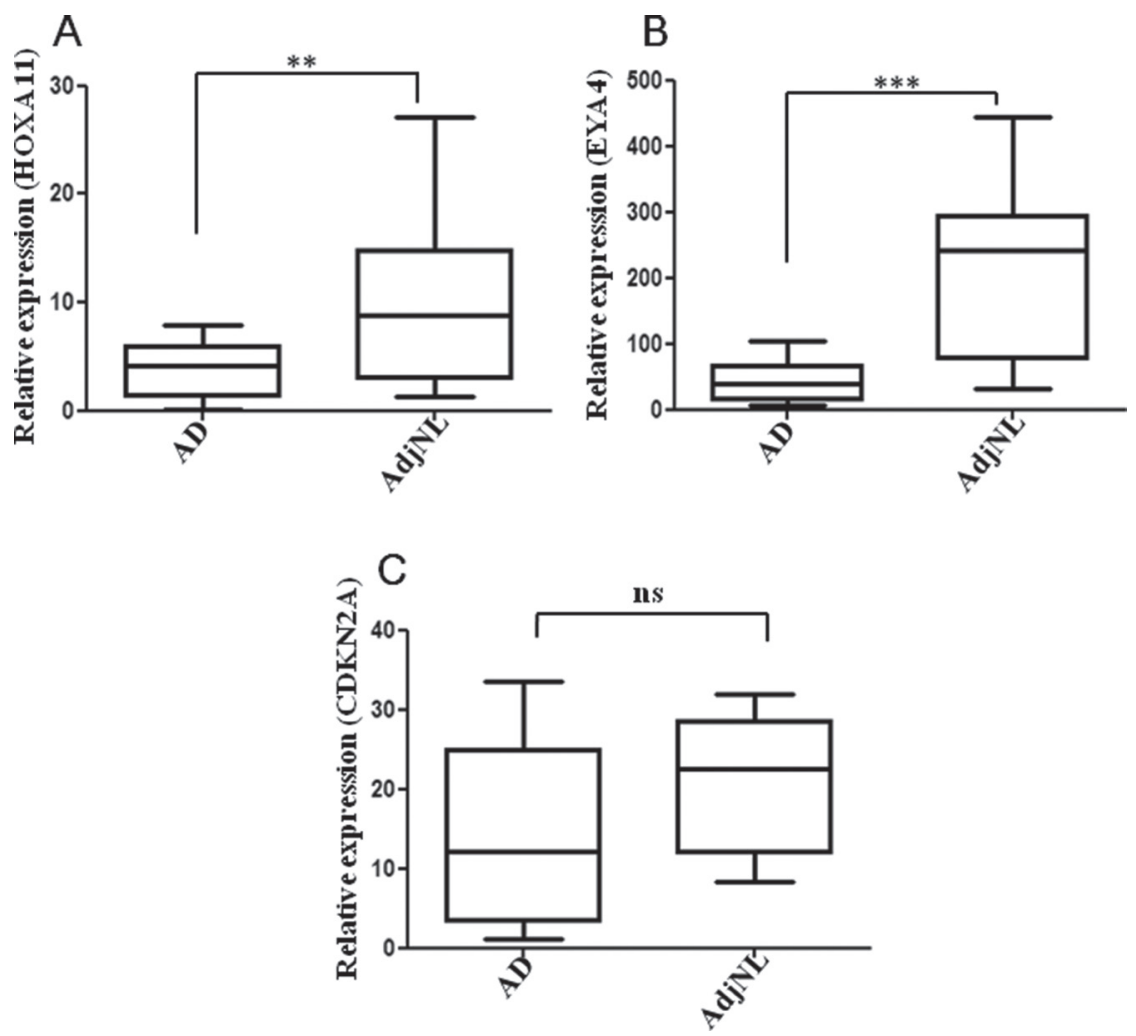

Figure 3: Real-time qPCR analysis of the (A) HOXA11, (B) EYA4 and (C) ENKN2A expression in AD and AdjNL tissues. All measurements are shown relative to the expression level of the GAPDH gene. Bars show the means $\pm \mathrm{SD}$. Difference was statistically significant $\left({ }^{*} p<0.01 .{ }^{*} p<0.001 .{ }^{* *} p<0.0001\right)$. (AD, AdjNL, 30 pairs tissues). 
A
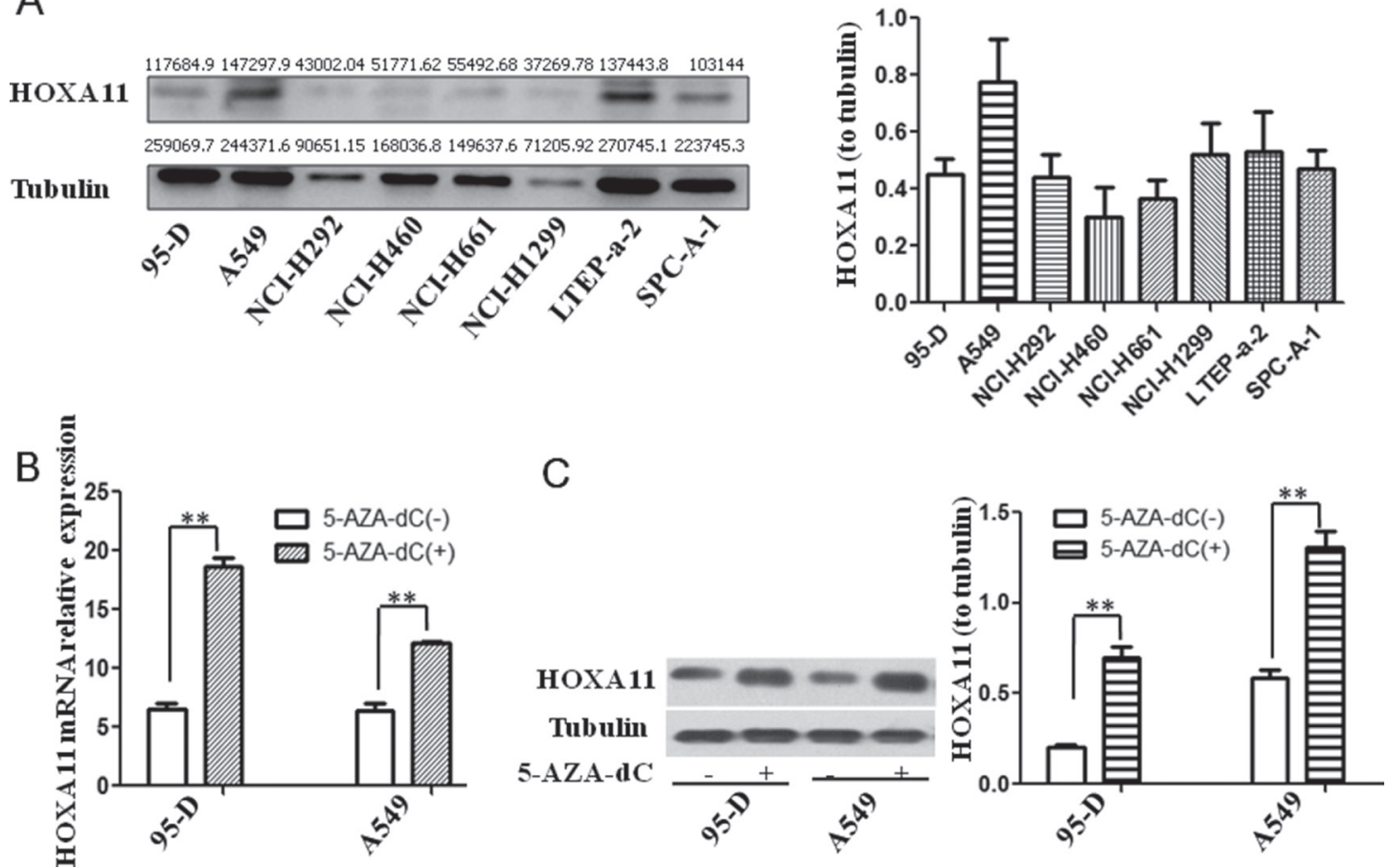

Figure 4: HOXA11 protein expression in lung cancer cell lines and effects of 5-Aza-dC on demethylation and reexpression of silenced HOXA11. (A) HOXA11 protein expression in lung cancer cell lines. We marked the gray value on each WB band using ImageJ analyzing. (B) Re-expression of silenced HOXA11 mRNA was examined by qPCR in lung AD cell lines (95D and A549) after the treatment of the cells with 5-AZA-dC for 48 hrs. (C) Re-expression of silenced HOXA11 protein was detected by Western blot analysis in lung AD cell lines (95D and A549) after the treatment of the cells with 5-AZA-dC for 48 hrs. (** $p<0.001$ ).

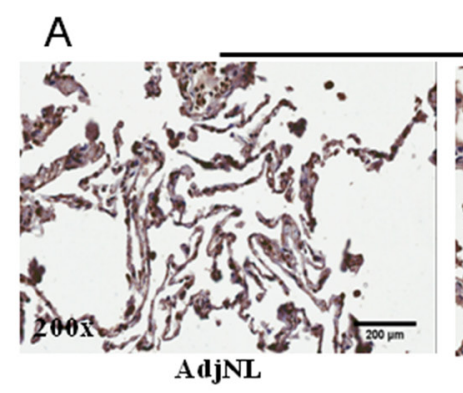

B

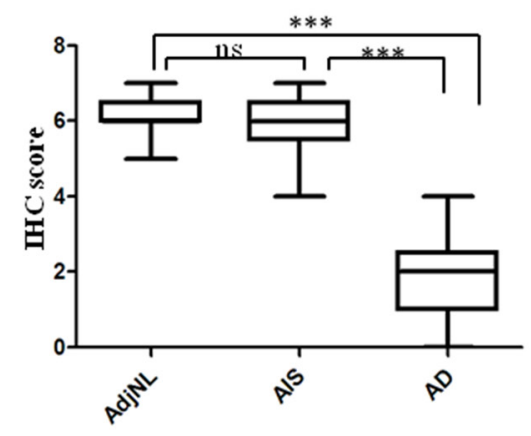

HOXA11

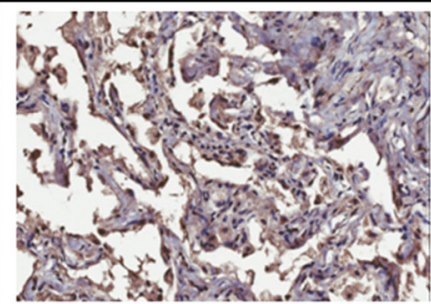

AIS
C

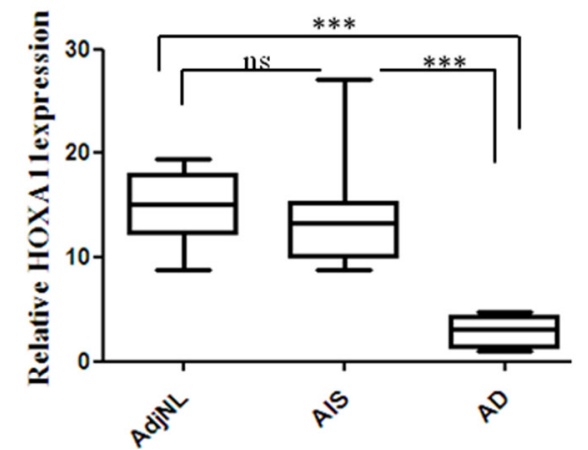

Figure 5: Immunohistochemical (IHC) staining of HOXA11 protein in lung tissues. (A) A strong staining in AdjNL. A strong staining in AIS. A weak staining in AD. (B) Boxplot of the HOXA11 IHC scores illustrated that AD had a lower HOXA11 protein level than AIS and AdjNL $(* * * p<0.0001)$. (C) Relative expression of HOXA11 in human lung AdjNL, AIS and AD tissues. Bars show the means \pm SD. Difference was statistically significant $\left(* p<0.01 .{ }^{*} p<0.001 . * * * p<0.0001\right)$. Original magnification, 200x. Scale bar, $200 \mu \mathrm{m}$. 
Finally, we analyzed the effect of HOXA11 hypermethylation on patient prognosis. We investigated the HOXA11 protein expression by IHC using samples from lung AIS and lung AD patients. Our results showed that the down-regulated expression of the HOXA11 gene could represent an independent unfavorable prognostic molecular marker for lung $\mathrm{AD}$. This study supported that HOXA11 might function as a tumor suppressive gene in lung $\mathrm{AD}$. Research by Mericskay M. et al. showed that a potential mechanism by which the HOXA11 gene is regulated by the formation of a regulatory loop between Wnt5a and Wnt7a in the mammalian female reproductive tract (FRT) [19]. Therefore, we hypothesized that the HOXA11 gene could be regulated by the formation of a loop between Wnt5a and Wnt7a in human lung cancer. In the further study, we intend to elucidate the exact regulatory mechanism and probably signaling pathways involved of the HOXA11 gene in human lung cancer.

In summary, our results showed that the promotor regions of HOXA11, CDKN2A EX2 and EYA4 were frequently methylated in human lung $\mathrm{AD}$ tissues. HOXA11 and CDKN2A EX2 could be confirmed as DNA hypermethylation markers for lung $\mathrm{AD}$. The expression of HOXA11 mRNA and protein was regulated by DNA methylation in promoter region in human lung tumor cell lines and human lung AIS and AD tissues. HOXA11 was a new valuable factor for predicting recurrence and survival in lung $\mathrm{AD}$ after surgical resection in clinical settings.

\section{MATERIALS AND METHODS}

\section{Patients and tissue specimens}

All samples were obtained from the human tumor bank at the Institute of Health Sciences, Shanghai Institutes for Biological Sciences. The tissues were bisected, one sample was collected, immediately snap-frozen in liquid nitrogen and then stored at $-80^{\circ} \mathrm{C}$ for further analysis; the other samples were fixed in $4 \%$ buffered formaldehyde and embedded in paraffin for further use. This study was approved by the institutional biomedical research ethics committee of the Shanghai Institutes for Biological Sciences (Chinese Academy of Sciences), and written informed consent was obtained from each patient. All cases were diagnosed histologically according to the World Health Organization classification [20] and the Noguchi classification [21] for small-sized AD.

\section{Genomic DNA extraction and bisulfite treatment}

In total, 21 pairs of formaldehyde fixed paraffin blocks of lung $\mathrm{AD}$ and AdjNL tissues and $2 \mathrm{NL}$ tissues were used for the MethyLight analysis. The patients' ages ranged from 45-82 years at the time of surgery (median: 65 years old). Hematoxylin and eosin-stained slides were reviewed by an experienced pathologist to confirm the original classification of the tumor and mark the lesions to be retrieved. DNA was extracted from manually microdissected tumor and nontumor lung samples under a microscope via proteinase $\mathrm{K}$ digestion [22]. Briefly, the cells were lysed in a solution containing $100 \mathrm{mmol} / \mathrm{L}$ Tris-Hcl (pH 8.0), $10 \mathrm{mmol} / \mathrm{L}$ EDTA (pH 8.0), $1 \mathrm{mg} / \mathrm{mL}$ proteinase $\mathrm{K}$, and $0.05 \mathrm{mg} / \mathrm{mL}$ tRNA and incubated at $50^{\circ} \mathrm{C}$ overnight. The bisulfate conversion was completed with the EZ DNA methylation ${ }^{\mathrm{TM}}$ kit (\#5001) (Zymo Research Corporation, CA. USA.) according to the manufacturer's instructions [23]. The bisulfite-treated DNA was subjected to quality control tests to determine the DNA amount and bisulfate conversion [9].

\section{DNA methylation analysis}

The DNA methylation analysis was performed using MethyLight [24]. The primer and probe sequences are listed in Supplementary Table 1. In addition to the primers and probe sets designed specifically for the genes of interest, an internal reference primer and probe set designed to analyze Alu repeats (Alu) were included in the analysis to normalize the input DNA [25]. The percentage methylated reference (PMR) was calculated as the $[\text { GENE } X]_{\text {sample }} /[\text { control }]_{\text {sample }}$ divided by $[\text { GENE } X]_{\text {Sssl }} /[\text { control }]_{\text {Sss }}$ (SssI treated human white blood DNA) and multiplied by 100 .

\section{Cell culture}

Eight human lung cancer cell lines (95-D, A549, NCI-H292, NCI-H460, NCI-H661, NCI-H1299, LTEP-a-2, and SPC-A-1) were purchased from the Type Culture Collection of the Chinese Academy of Sciences, Shanghai, China. All cell lines were grown in RPMI-1640 (HyClone) supplemented with 10\% fetal bovine serum (FBS) (GIBCO) and $100 \mathrm{U} / \mathrm{ml}$ penicillin and streptomycin $(\mathrm{P} / \mathrm{S})$. All cell lines were incubated at $37^{\circ} \mathrm{C}$ with $5 \% \mathrm{CO} 2$.

\section{5-Aza-2'-deoxycytidine treatment}

The lung AD cell lines 95-D and A549 were treated with a culture medium containing a demethylating agent, 5-aza-2'-deoxycytidine (5-Aza-dC; Sigma-Aldrich, USA). 5-Aza-dC was dissolved in dimethyl sulfoxide (DMSO). The 95-D and A549 cells $\left(1 \times 10^{6}\right.$ cells $/ 100 \mathrm{~mm}$ dish $)$ were incubated in a culture medium with 5-Aza-dC (final concentration of $2 \mu \mathrm{mol} / \mathrm{L}$ ) and without 5-Aza-dC (DMSO; final concentration of $2 \mu \mathrm{mol} / \mathrm{L}$ ) for $48 \mathrm{hrs}$. The culture medium was changed every day. After harvesting the cells, RNA was extracted as described below for reverse transcription Quantitative real-time-PCR (RT-qPCR), and protein was extracted for the Western blotting analysis.

\section{RNA isolation and RT-qPCR}

In total, 30 pairs of frozen lung AD tissues and adjacent non-tumor tissues were used to detect the 
expression of the HOXA11, EYA4 and CDKN2A EX2 genes by RT-qPCR. Total RNA was isolated with TRIzol Reagent (Invitrogen/Thermo Fisher Scientific, Waltham, MA) according to the manufacturer's instructions, and the samples were stored at $-80^{\circ} \mathrm{C}$ until use. Reverse transcription was performed using the PrimeScript RT Reagent Kit (TaKaRa, Shiga, Japan). Quantitative PCR was carried out using the SYBR Green PCR Master Mix (TaKaRa) in the ABI Prism7900 (Applied Biosystems/ Thermo Fisher Scientific, Waltham, MA). All gene expression results were normalized to the expression of the housekeeping gene GAPDH. The PCR primers are shown in Supplementary Table 2.

\section{Protein extraction and western blotting analysis}

Protein samples from the cell lines and tissues were prepared with a lysis buffer, M-PER (PIERCE Biotechnology, Rockford, IL, USA), containing proteinase inhibitors. Total protein aliquots were mixed with the Laemmli sample buffer, denatured at $95^{\circ} \mathrm{C}$ for $5 \mathrm{~min}$ and separated on a $10 \%$ Tris- $\mathrm{HCl}$ gel (Bio-Rad). The proteins were transferred to polyvinylidene difluoride membranes and blocked with $5 \%(\mathrm{w} / \mathrm{v})$ nonfat milk/TBST for $1 \mathrm{~h}$ at room temperature. The membranes were incubated overnight at $4{ }^{\circ} \mathrm{C}$ with primary antibodies directed against HOXA11 (1:5000, ab28699, Abcam, USA) in 5\% BSA/TBST (w/v). The membranes were washed three times with TBST and incubated with an HRP-linked secondary antibody for $1 \mathrm{~h}$ at room temperature. The protein bands were visualized using electro-chemiluminescence (ImageQuant LAS4000, USA). The anti-Tubulin antibodies served as the loading control.

\section{Immunohistochemistry of formalin-fixed tissue microarray (TMA) sections}

Paraffin-embedded TMA blocks, including 160 lung adenocarcinoma samples (40 lung AIS, 40 lung $\mathrm{AD}$ and 80 normal counterparts), were sectioned at a $4 \mu \mathrm{m}$ thickness, deparaffinized in xylene, and rehydrated in graded ethanol solutions, and the endogenous peroxidase activity was blocked by incubation with $3 \%$ $\mathrm{H}_{2} \mathrm{O}_{2}$ for $30 \mathrm{~min}$ at room temperature. Then, the sections were immersed in a citrate- $\mathrm{NaOH}$ buffer $(10 \mathrm{mM}$ sodium citrate, $\mathrm{pH} \mathrm{7.0)} \mathrm{for} 40 \mathrm{~min}$ at $92^{\circ} \mathrm{C}$ to restore antigenicity. The rehydrated sections were incubated overnight at $4^{\circ} \mathrm{C}$ with the rabbit anti-human HOXA11 polyclonal antibody (1:250, ab28699, Abcam, USA.). The sections incubated with the first antibody were washed with Tris-buffered saline (TBS) and were then incubated with the MaxVision ${ }^{\mathrm{TM}}$ HRP-Polymer anti-Rabbit IHC Kit (Maixin, Fuzhou, China) for $15 \mathrm{~min}$ at room temperature. The sections were visualized using the DAB Detection Kit (Maixin, Fuzhou, China), and the reaction was followed by counterstaining with hematoxylin. The negative control experiments were performed by omitting the primary antibody.

\section{Scoring of HOXA11 expression}

The evaluation of the immunohistochemical staining was performed independently by two authors without knowledge of the clinicpathological information. The immunoreactive scores of HOXA11 were determined by the sum of extension and intensity. The intensity of the staining was scored using the following scale: 0 , no staining; +, mild staining; ++, moderate staining and +++, marked staining. The area of staining was evaluated and recorded as a percentage: 0 , less than $5 \% ;+, 5 \%-25 \%$; ++, $26 \%-50 \% ; 3+, 51 \%-75 \%$ and $4+$, more than $75 \%$. The combined scores were recorded and graded as follows: -, $0 ;+, 1-2 ;++, 3-5 ;+++, 6-7$.

\section{Statistical analyses}

All statistical analyses used in this paper are two side $T$ test. $p<0.05$ shows significant difference. Receiver operating characteristic (ROC) curves were plotted using the AD vs. AdjNTL lung PMR value by SPSS software (SPSS Inc., Chicago, IL, USA). The two-dimensional hierarchical clustering of samples and methylated genes were analyzed by the R programming language (R 3.0.1).

\section{ACKNOWLEDGMENTS AND FUNDING}

This research was supported by National key program (973) for Basic Research of China (2011CB510106) and the open subject of Chinese academy of sciences (No.201501 and No.201601).

\section{CONFLICTS OF INTEREST}

The authors have no conflicts of interest with the studies presented here.

\section{REFERENCES}

1. Travis WD, Travis LB, Devesa SS. Lung cancer. Cancer. 1995; 75:191-202.

2. Chen Z, Fillmore CM, Hammerman PS, Kim CF, Wong KK. Non-small-cell lung cancers: a heterogeneous set of diseases. Nat Rev Cancer. 2014; 14:535-46.

3. Noguchi M. Stepwise progression of pulmonary adenocarcinoma-clinical and molecular implications. Cancer Metastasis Rev. 2010; 29:15-21.

4. Ellis JR, Gleeson FV. Lung cancer screening. Br J Radiol. 2001; 74:478-85.

5. Marcus PM. Lung cancer screening: an update. J Clin Oncol. 2001; 19:83S-86S.

6. Noguchi M, Morikawa A, Kawasaki M, Matsuno Y, Yamada T, Hirohashi S, Kondo H, Shimosato Y. Small adenocarcinoma of the lung. Histologic characteristics and prognosis. Cancer. 1995; 75:2844-52. 
7. Kerr KM, Galler JS, Hagen JA, Laird PW, Laird-Offringa IA. The role of DNA methylation in the development and progression of lung adenocarcinoma. Dis Markers. 2007; 23:5-30.

8. Laird PW. The power and the promise of DNA methylation markers. Nat Rev Cancer. 2003; 3:253-66.

9. Campan M, Weisenberger DJ, Trinh B, Laird PW. MethyLight. In: Tost J, editor. DNA Methylation: Methods and Protocols. Totowa (NJ): Humana Press. 2009; pp. 325-37.

10. Merlo A, Herman JG, Mao L, Lee DJ, Gabrielson E, Burger PC, Baylin SB, Sidransky D. 5' CpG island methylation is associated with transcriptional silencing of the tumour suppressor p16/CDKN2/MTS1 in human cancers. Nat Med. $1995 ; 1: 686-92$.

11. Sun W, Iijima T, Kano J, Kobayashi H, Li D, Morishita Y, Okubo C, Anami Y, Noguchi M. Frequent aberrant methylation of the promoter region of sterile $\alpha$ motif domain 14 in pulmonary adenocarcinoma. Cancer Sci. 2008; 99:2177-84.

12. Feinberg AP, Ohlsson R, Henikoff S. The epigenetic progenitor origin of human cancer. Nat Rev Genet. 2006; $7: 21-33$

13. Das PM, Singal R. DNA methylation and cancer. J Clin Oncol. 2004; 22:4632-42.

14. Selamat SA, Galler JS, Joshi AD, Fyfe MN, Campan M, Siegmund KD, Kerr KM, Laird-Offringa IA. DNA methylation changes in atypical adenomatous hyperplasia, adenocarcinoma in situ, and lung adenocarcinoma. PLoS One. 2011; 6:e21443.

15. Hwang JA, Lee BB, Kim Y, Park SE, Heo K, Hong SH, Kim YH, Han J, Shim YM, Lee YS, Kim DH. HOXA11 hypermethylation is associated with progression of nonsmall cell lung cancer. Oncotarget. 2013; 4:2317-25. doi: 10.18632/oncotarget.1464.

16. Qian YQ, Billeter M, Otting G, Müller M, Gehring WJ, Wüthrich K. The structure of the Antennapedia homeodomain determined by NMR spectroscopy in solution: comparison with prokaryotic repressors. Cell. 1989; 59:573-80.
17. Szczepańska M, Wirstlein P, Skrzypczak J, Jagodziński PP. Expression of HOXA11 in the mid-luteal endometrium from women with endometriosis-associated infertility. Reprod Biol Endocrinol. 2012; 10:1.

18. Tsou JA, Galler JS, Siegmund KD, Laird PW, Turla S, Cozen W, Hagen JA, Koss MN, Laird-Offringa IA. Identification of a panel of sensitive and specific DNA methylation markers for lung adenocarcinoma. Mol Cancer. 2007; 6:70.

19. Mericskay M, Kitajewski J, Sassoon D. Wnt5a is required for proper epithelial-mesenchymal interactions in the uterus. Development. 2004; 131:2061-72.

20. Brambilla E, Travis WD, Colby TV, Corrin B, Shimosato Y. The new World Health Organization classification of lung tumours. Eur Respir J. 2001; 18:1059-68.

21. Travis WD, Brambilla E, Noguchi M, Nicholson AG, Geisinger KR, Yatabe Y, Beer DG, Powell CA, Riely GJ, Van Schil PE, Garg K, Austin JH, Asamura H, et al. International association for the study of lung cancer/ american thoracic society/european respiratory society international multidisciplinary classification of lung adenocarcinoma. J Thorac Oncol. 2011; 6:244-85.

22. Laird PW, Zijderveld A, Linders K, Rudnicki MA, Jaenisch R, Berns A. Simplified mammalian DNA isolation procedure. Nucleic Acids Res. 1991; 19:4293.

23. Eads CA, Danenberg KD, Kawakami K, Saltz LB, Blake C, Shibata D, Danenberg PV, Laird PW. MethyLight: a highthroughput assay to measure DNA methylation. Nucleic Acids Res. 2000; 28:E32.

24. Tsou JA, Hagen JA, Carpenter CL, Laird-Offringa IA. DNA methylation analysis: a powerful new tool for lung cancer diagnosis. Oncogene. 2002; 21:5450-61.

25. Weisenberger DJ, Campan M, Long TI, Kim M, Woods C, Fiala E, Ehrlich M, Laird PW. Analysis of repetitive element DNA methylation by MethyLight. Nucleic Acids Res. 2005; 33:6823-36. 